\title{
Ohio Community Pharmacist Interest and Participation in Community-Clinical Linkages
}

\author{
Scott J. Alexander, PharmD Candidate, Ohio Northern University
}

Natalie A. DiPietro Mager, PharmD, MPH, Associate Professor, Pharmacy Practice, Ohio Northern University

\begin{abstract}
Background: Community-clinical linkages have been promoted as a means to improve population health. The community pharmacy is an ideal location for these partnerships to occur due to the expertise of the community pharmacist. While the need for these partnerships exists, there are limited data regarding community pharmacists' current participation in such programs.

Objective: The purpose of this analysis was to assess Ohio community pharmacists' involvement and interest in community-clinical linkages.

Methods: An electronic survey tool containing 26 questions was developed to assess Ohio community pharmacists' participation in community-clinical linkages and interest to develop such partnerships. The tool was sent via email to a random sample of 500 pharmacists registered in Ohio and practicing in a community setting. Chi-square or Fisher exact nonparametric statistical tests were used as appropriate to identify whether there were any significant differences in current partnership or interest to partner with a prescriber who refers patients to their community pharmacy based on education (Bachelor of Science or Doctor of Pharmacy degree) or pharmacy location (urban, suburban, or rural).

Results: Nine emails were undeliverable, leaving a sample of 491 pharmacists. Ninety-three (19\%) responded to the survey. Sixteen respondents (17\%) indicated that they currently partner with a prescriber who refers patients to their pharmacy for assistance with medications or chronic disease state management; this practice was more often reported in urban settings ( $p=0.022)$. Of those not currently participating in such a partnership, 53 (57\%) were interested in developing one. Thirty-two respondents (34\%) reported providing referrals for at least 1 type of screening or counseling service. For some types of services, pharmacists reported that they provide the service in the pharmacy and/or were interested to develop the service in the pharmacy rather than provide a referral. However, for any given service there were a number of pharmacists who expressed interest in providing referrals although they were not currently doing so.

Conclusion: This sample of Ohio community pharmacists reported limited participation in community-clinical linkages but interest to develop them. Further studies should explore the pharmacists' role and impact in such programs.
\end{abstract}

Keywords: community pharmacy services; referral and consultation; population health management

\section{Introduction}

Community-clinical linkages are connections between the community, clinics, and other primary care settings that help to ensure that those at high risk for chronic diseases and subsequent complications have access in the community to quality resources to best prevent, delay, or manage their conditions. Access, referral, and payment for services may be facilitated through community-clinical linkages, thereby improving patient outcomes and population health. ${ }^{1-5}$

Community pharmacies can be an integral part of communityclinical linkages (Figure 1). For example, recent reports by the Centers for Disease Control and Prevention (CDC) provide a blueprint for integrating community pharmacists into community-clinical linkages with public health and clinical sectors. The CDC indicates multiple ways in which community

\section{Corresponding author:}

Natalie A. DiPietro Mager, PharmD, MPH

525 S. Main St., Ada, OH 45810 USA

Phone: +1-419-772-3971

Email: n-dipietro@onu.edu pharmacists and physicians in primary care offices and hospitals can interface in community-clinical linkages to increase access to quality care, including (1) health assessment in the community pharmacy with referral (as needed) to a physician for diagnosis or treatment and (2) physician referral of patients to the community pharmacist for assistance with medications or chronic disease state management. ${ }^{2-4}$

Currently, there is great need in the United States (U.S.) for community-clinical linkages to be formed. ${ }^{1-5}$ For example, a recent article in Health Affairs showed that only $8 \%$ of adults in the U.S. 35 years and older had received all of recommended clinical preventive services in $2015 .{ }^{6}$ There are also ample opportunities for such partnerships to be formed, given that the average American lives within 5 miles of a community pharmacy. ${ }^{7}$ However, there are limited data regarding community pharmacist participation in community-clinical linkages or interest in establishing such programs. Therefore, the purpose of this analysis was to assess Ohio community pharmacists' involvement and interest in community-clinical linkages with the clinical sector.

\section{Methods}

A survey tool was developed to assess Ohio community pharmacists' provision of clinical preventive services as well as 
participation and interest in community-clinical linkages. The tool utilized selected clinical preventive services ${ }^{8}$ recommended by the U.S. Preventive Services Task Force as a framework. The tool contained 26 questions with 13 demographic questions, 6 questions assessing pharmacists' practices, and 7 questions soliciting opinions pharmacists held on these services.

The tool was entered into Qualtrics Labs (Provo, UT) for distribution via e-mail. Six pharmacists who had backgrounds in community pharmacy pilot-tested the survey before distribution. The objectives of the pilot-testing were twofold: (1) to check the face validity of the questions and (2) to test for any technical difficulties in the survey.

Following completion of pilot testing, the survey was sent electronically to a sample of 500 randomly-selected pharmacists registered with the Ohio State Board of Pharmacy and currently practicing in a community pharmacy in Ohio. As there may be a lack of familiarity among pharmacists regarding the term "community-clinical linkages", the survey cover letter did not explicitly state the focus of the survey questions but rather indicated that the survey focused on "community pharmacy services."

Reminder emails were sent every 3-4 days, and the survey was closed after one month. No incentives were given for survey completion. Surveys were completed anonymously. The Ohio Northern University Institutional Review Board approved the study.

Microsoft Office Excel 2013 (Redmond, WA) was used for descriptive statistics, and IBM SPSS 22 (Armonk, NY)/Vassarstats (Poughkeepsie, NY) were used for analytic statistics. Chi-square or Fisher exact nonparametric statistical tests were used as appropriate to identify whether there were any significant differences in current partnership or interest to partner with a prescriber who refers patients to their community pharmacy based on education (Bachelor of Science or Doctor of Pharmacy degree) or pharmacy location (urban, suburban, or rural). Statistical significance was defined a priori as a $p$-value of $<0.05$.

\section{Results}

Ninety-three community pharmacists responded to the survey (Table 1). Since 9 emails were undeliverable, this gave a response rate of $19 \%$. Detailed information regarding respondents' direct provision of clinical preventive services that can be provided in a community pharmacy has already been reported. ${ }^{9}$

In regards to community-clinical linkages, 16 (17\%) of respondents indicated that they currently partner with a prescriber who refers patients to their community pharmacy for assistance with medications or chronic disease state management. Community pharmacists at urban locations reported such relationships more often than those at suburban or rural locations $(p=0.022)$; there was no significant difference seen by education $(p=0.316)$. Fifty-three $(57 \%)$ of those who are not currently participating in such a partnership reported being interested to develop one; no significant differences were seen based on education $(p=0.542)$ or pharmacy location $(p=0.231)$.

Another aspect of community-clinical linkages are referrals by the community pharmacist to the clinical sector. Thirty-two respondents (34\%) reported providing referrals for at least 1 type of service. There are a number of recommended counseling and screening services that could potentially be provided in the community pharmacy (Figure 2). Between $4 \%$ to $9 \%$ of respondents indicated that they currently provide referrals for these types of services. Respondents reported a greater interest in developing the service to be delivered in their own pharmacy, rather than developing a referral process to another source, for each of the 9 counseling services (Table 2) and 7 of the 12 screening services (Table 3) assessed. However, there were 5 screening services for which slightly more respondents indicated an interest in providing a referral than in developing the service themselves: depression, hepatitis C, HIV, intimate partner violence, and tuberculosis (Table 3). Additionally, community pharmacist interest and participation in referrals for screening services that are not typically feasible to be offered in community pharmacies (Figure 2) was assessed. Between $2 \%$ to $4 \%$ of respondents reported currently providing referrals for these types of services, with approximately $24 \%$ of respondents indicating an interest to provide referrals although not currently doing so (Table 4).

\section{Discussion}

There are many potential roles for community pharmacists participating in community-clinical linkages with the clinical sector, including triaging of patients to the most appropriate source of care, referring patients to physicians or prescribers, and collaborating with prescribers to manage patients' medications and chronic conditions..$^{2-4}$ Community pharmacists can help fill the gap in provision of clinical preventive services, either through directly providing the service themselves if feasible or by referring patients to other sources to receive necessary care. ${ }^{10}$ These types of partnerships can result in increased access to care and improved patient outcomes. ${ }^{2-4}$ Overall, respondents to this survey indicated low involvement in community-clinical linkages with the clinical sector but interest to develop them.

While only $17 \%$ of community pharmacists reported partnerships with a prescriber who refers patients to their pharmacy for disease state management or medication management, $57 \%$ reported interest to develop such partnerships. Resources such as those published by the CDC that are specific to community pharmacies and physicians may be helpful to those wanting to form such partnerships. ${ }^{2-3}$ 
Currently, those types of partnerships were more often reported among community pharmacists working in urban areas; there is a need to develop these partnerships especially in rural areas where the population tends to have higher rates of chronic disease, poorer overall health status, and fewer physician resources as compared to those living in urban areas. ${ }^{11,12}$ A clear and strong partnership should be developed so as to ensure a high rate of prescriber acceptance of pharmacist recommendations. ${ }^{2,3,13,15}$

Interestingly, for some types of services more community pharmacists reported wanting to develop them rather than refer patients to another source. Often-reported barriers to pharmacists creating new clinical services in the community pharmacy setting in the U.S. are time, space, and lack of staffing and reimbursement. ${ }^{15}$ These barriers need to be addressed so that pharmacists can provide comprehensive clinical preventive services to their patients. A potential area for future research is to more fully explore what factors influence pharmacist interest in developing the service in the pharmacy rather than develop partnerships to refer patients to established providers.

Regardless, there is an opportunity to educate community pharmacists regarding the important role they play in community-clinical linkages and to encourage them to refer patients as appropriate to the clinical sector. There are some services that cannot fully be provided in the community pharmacy setting; for example, while there are reports of community pharmacist involvement in early detection activities for certain cancers, referrals for tests such as mammograms or colonoscopies will be required. ${ }^{16,17}$ Similarly, while there is potential for community pharmacists to provide screenings for sexually transmitted infections such as chlamydia and gonorrhea in the pharmacy, ${ }^{18}$ the practice is not currently widespread in the U.S. outside of sale of over-the-counter testing kits. The number of respondents currently providing referrals for these types of screenings was quite low, but about $24 \%$ of respondents were interested to create them. Community pharmacists should be encouraged to develop such referral services by reaching out to potential partners in the area to understand the varied services available to their patients.

In addition, for some types of services (e.g., tobacco use counseling, screening for tobacco use, blood pressure screening) a sizeable number of pharmacists reported currently providing those services in the community pharmacy, which would naturally limit interest in developing referrals for these services. However, there are many related aspects that should be explored in future research. For example, previous reviews have determined low uptake of patients following through with the referrals to other healthcare providers provided by community pharmacists; ${ }^{15,19,20}$ therefore, even though blood pressure or tobacco use screenings are being performed in the community pharmacy, what process should be developed to ensure patients take their screening results to a prescriber for follow-up? What processes can be developed to avoid silos and to better integrate community pharmacies in the U.S. into a health information exchange, facilitating information exchange between community pharmacies and clinical and public health sectors? ${ }^{21}$ Pharmacists participating in community-clinical linkages may utilize novel practice models such as collaborative practice agreements and/or medication therapy management. ${ }^{2}$ These types of practice models and the impact on patient receipt of clinical preventive services and appropriate treatment should be more fully studied.

Furthermore, this survey only focused on linkages between community pharmacies and the clinical sector. There are opportunities for community pharmacies to participate in community-clinical linkages with public health and communitybased organizations. ${ }^{4,22}$ For example, a recent toolkit developed by the National WIC Association (the non-profit education component of the Special Supplemental Nutrition Program for Women, Infants and Children [WIC]) highlighted community pharmacies as a potential partner in community-clinical linkages. ${ }^{23}$ Additional research to describe pharmacist participation in and best practices for such partnerships is warranted.

Limitations to this study include response rate and possible response bias; therefore, results may not be generalizable to all community pharmacists practicing in Ohio. Additionally, as pharmacist scope-of-practice varies by state and country, results may not be applicable to community pharmacists practicing in different parts of the U.S. or other nations. As this was a preliminary study, there were no available data from which to draw sample size calculations. As a result, the analysis of the survey data is subject to type 2 error.

\section{Conclusion}

Community-clinical linkages have been promoted as a means to improve population health. Community pharmacists can play an important role in filling gaps in preventive services by increasing patient access to care by either providing a service in the pharmacy or referring patients to partners in the clinical sector. Additionally, prescribers can refer patients to the pharmacy to manage their disease states and medications. This analysis provided preliminary information on community pharmacists involvement in these types of community-clinical linkages. This sample of Ohio community pharmacists reported limited participation in community-clinical linkages but interest to develop them. Further studies should explore the pharmacists' role and impact in such programs. 
Conflict of interest statement: No conflicts of interest to disclose

Treatment of Human Subjects: The study was approved by the Ohio Northern University IRB.

Previous presentation: A subset of these data were presented at the American Pharmacists Association Annual Meeting, March 2018 and the American Public Health Association Annual Meeting, November 2018

\section{References}

1. Clinical-community linkages. Agency for Healthcare Research and Quality, Rockville, MD. http://www.ahrq.gov/professionals/prevention-chroniccare/improve/community/index.html. Content last reviewed December 2016; accessed 23 February 2019.

2. Centers for Disease Control and Prevention. Creating community-clinical linkages between community pharmacists and physicians. Atlanta, GA: Centers for Disease Control and Prevention, U.S. Department of Health and Human Services; 2017.

https://www.cdc.gov/dhdsp/pubs/docs/ccl-pharmacyguide.pdf

3. Centers for Disease Control and Prevention. Communityclinical linkages for the prevention and control of chronic diseases: A practitioner's guide. Atlanta, GA: Centers for Disease Control and Prevention, U.S. Department of Health and Human Services; 2016. https://www.cdc.gov/dhdsp/pubs/docs/ccl-practitionersguide.pdf

4. Centers for Disease Control and Prevention. Methods and resources for engaging pharmacy partners. Atlanta, GA: Centers for Disease Control and Prevention, U.S. Department of Health and Human Services; 2016. https://www.cdc.gov/dhdsp/pubs/docs/engagingpharmacy-partners-guide.pdf

5. Centers for Disease Control and Prevention. Partnering with pharmacists in the prevention and control of chronic diseases: A program guide for public health. Atlanta, GA: Centers for Disease Control and Prevention, U.S. Department of Health and Human Services; 2012. https://www.cdc.gov/dhdsp/programs/spha/docs/pharmac ist guide.pdf

6. Borsky A, Zhan C, Miller T, Ngo-Metzger Q, Bierman AS, Meyers D. Few Americans receive all high-priority, appropriate clinical preventive services. Health Aff (Millwood). 2018 Jun;37(6):925-928.

7. DeArment A. Pharmacists are face of health care in community. Drug Store News. 2012;3:4e5.

8. DiPietro Mager NA, Bright DR, Murphy BL, Rondon-Begazo A, Kelling SE. Opportunities for pharmacists and student pharmacists to provide clinical preventive services. Innov Pharm. 2017;8(1): Article 11.

9. Alexandar SJ, DiPietro Mager NA. Ohio community pharmacist provision of clinical preventive services. Innov Pharm. 2019;10(1): Article 12.

10. Kelling SE, Rondon-Begazo A, DiPietro Mager NA, Murphy $B L$, Bright DR. Provision of clinical preventive services by community pharmacists. Prev Chronic Dis. 2016;13:E149.
11. Gilbert $\mathrm{S}$. The Role of the Rural Pharmacist. https://imedicare.com/articles/the-role-of-the-ruralpharmacist/. Content last reviewed August 2016; accessed 23 February 2019.

12. Rural Health Disparities. Rural Health Information Hub. https://www.ruralhealthinfo.org/topics/rural-healthdisparities. Content last reviewed November 2017; accessed 23 February 2019.

13. Kellerman R, Kirk L. Principles of the patient-centered medical home. Am Fam Physician. 2007;76:774-775.

14. Blalock SJ, Roberts AW, Lauffenburger JC, Thompson T, O'Connor SK. The effect of community pharmacy-based interventions on patient health outcomes: A systematic review. Med Care Res Rev. 2013;70(3):235-266.

15. Melton B, Lai Z. Review of community pharmacy services: What is being performed, and where are the opportunities for improvement? Integr Pharm Res Pract. 2017;6: 79-89.

16. San-Juan-Rodriguez A, Newman TV, Hernandez I, Swart ECS, Klein-Fedyshin M, Shrank WH, Parekh N. Impact of community pharmacist-provided preventive services on clinical, utilization, and economic outcomes: An umbrella review. Prev Med. 2018;115:145-155.

17. Lindsey L, Husband A, Nazar H, Todd A. Promoting the early detection of cancer: A systematic review of community pharmacy-based education and screening interventions. Cancer Epidemiol. 2015;39(5):673-81.

18. Wood H, Gudka S. Pharmacist-led screening in sexually transmitted infections: Current perspectives. Integr Pharm Res Pract. 2018;7:67-82.

19. Willis A, Rivers P, Gray LJ, Davies M, Khunti K. The Effectiveness of screening for diabetes and cardiovascular disease risk factors in a community pharmacy setting. PLoS One, 2014; 9: Article e91157.

20. Ayorinde AA, Porteous T, Sharma P. Screening for major diseases in community pharmacies: A systematic review. Int J Pharm Pract. 2013;21:349-361.

21. Krist AH, Shenson D, Woolf $\mathrm{SH}$, et al. Clinical and community delivery systems for preventive care: An integration framework. Am J Prev Med. 2013;45(4):508-16.

22. Lindell V, Kelling SE, Azar M, Telega E. Review of community based organization and community pharmacy partnerships for preventive care services. Innov Pharm. 2018;9(2):Article 8.

23. Society for Public Health Education and National WIC Association. Integrating services for community health: $A$ community-clinical linkages toolkit for local WIC agencies. Washington, D.C.: Society for Public Health Education and National WIC Association; 2017.

https://www.sophe.org/wpcontent/uploads/2017/07/National-WICAssociation final2.pdf 
Figure 1. Examples of linkages between the community and clinical sector ${ }^{3}$

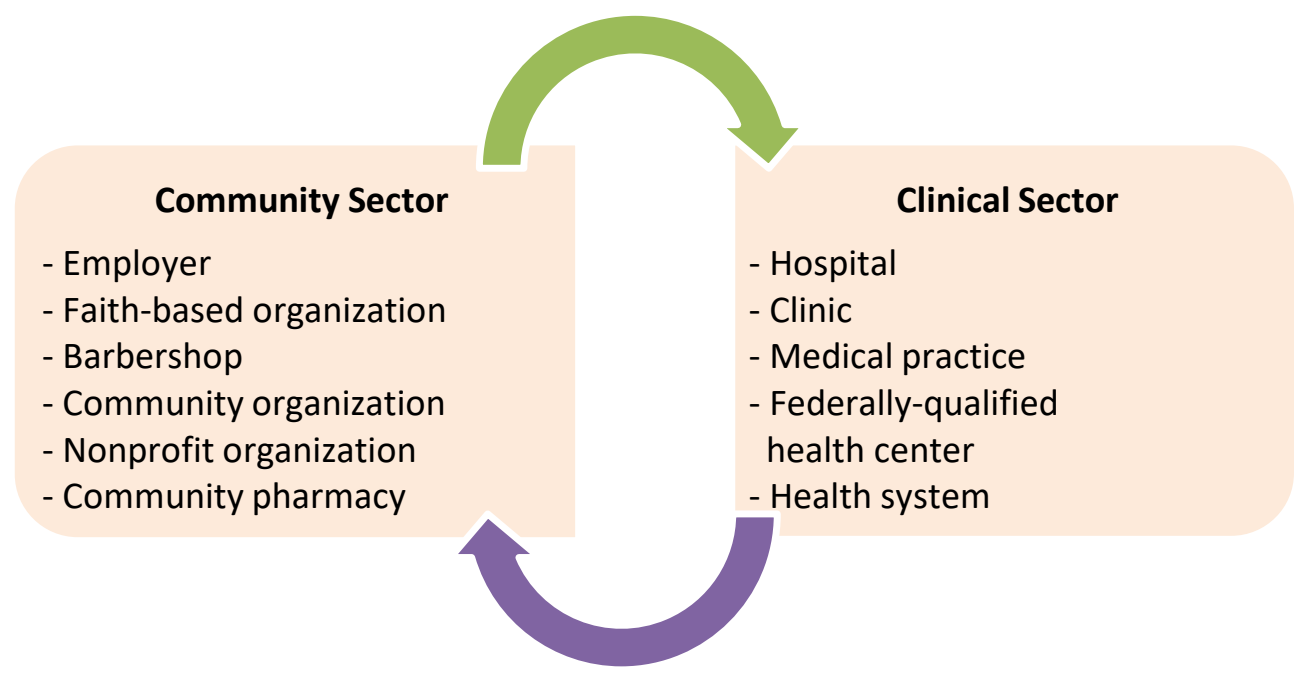

Figure 2. Selected counseling and screening services recommended by the U.S. Preventive Services Task Force for the general, adult population ${ }^{6}$

Counseling services: Alcohol misuse; Birth defect prevention (folic acid); Breastfeeding; Diet; Fall prevention; Physical activity; Skin cancer prevention; Sexually transmitted infection prevention; Tobacco use

Screening services: Alcohol misuse; Blood pressure; Cholesterol; Depression; Hepatitis C; HIV; Intimate partner violence; Obesity; Osteoporosis; Tobacco use; Type 2 diabetes; Tuberculosis
Screening services: Abdominal aortic aneurysm; BRCA risk assessment and testing; Breast cancer; Cervical cancer; Colorectal cancer; Lung cancer; Sexually trnasmitted infections (i.e., chlamydia, gonorrhea, syphilis) 
Table 1. Characteristics of survey respondents $(n=93)$

\begin{tabular}{|c|c|}
\hline Characteristic & $\mathrm{n}(\%)$ \\
\hline $\begin{array}{l}\text { Gender } \\
\text { Male } \\
\text { Female } \\
\text { Prefer not to answer }\end{array}$ & $\begin{array}{c}33(35) \\
59(64) \\
1(1)\end{array}$ \\
\hline $\begin{array}{l}\text { Education* } \\
\text { Bachelor of Science in Pharmacy } \\
\text { Doctor of Pharmacy } \\
\text { Residency }\end{array}$ & $\begin{array}{c}50(54) \\
48(52) \\
2(2)\end{array}$ \\
\hline $\begin{array}{l}\text { Years in Practice } \\
5 \text { years or less } \\
6-10 \text { years } \\
11-20 \text { years } \\
\text { More than } 20 \text { years }\end{array}$ & $\begin{array}{l}25(27) \\
19(20) \\
13(14) \\
36(39)\end{array}$ \\
\hline $\begin{array}{l}\text { Position* } \\
\text { Staff pharmacist } \\
\text { Pharmacy manager } \\
\text { Clinical/MTM pharmacist }\end{array}$ & $\begin{array}{l}52(56) \\
42(45) \\
11(12)\end{array}$ \\
\hline $\begin{array}{l}\text { Employment status } \\
\text { Full-time } \\
\text { Part-time }\end{array}$ & $\begin{array}{l}82(88) \\
11(12) \\
\end{array}$ \\
\hline $\begin{array}{l}\text { Location } \\
\text { Rural } \\
\text { Suburban } \\
\text { Urban } \\
\end{array}$ & $\begin{array}{l}23(25) \\
44(47) \\
26(28)\end{array}$ \\
\hline $\begin{array}{l}\text { Practice Setting } \\
\text { Chain pharmacy (e.g., CVS, Walgreens, etc) } \\
\text { Grocery (e.g., Kroger, Giant Eagle, etc) } \\
\text { Mass merchandiser (ex: Walmart, Kmart, etc) } \\
\text { Independent pharmacy } \\
\text { Blank }\end{array}$ & $\begin{array}{c}39(42) \\
26(28) \\
10(11) \\
16(17) \\
2(2)\end{array}$ \\
\hline
\end{tabular}

* Respondents could select $>1$ choice 
Table 2. Ohio community pharmacist $(n=93)$ responses regarding counseling services

\begin{tabular}{|c|c|c|c|c|c|c|}
\hline Service & $\begin{array}{l}\text { Currently } \\
\text { provide } \\
\text { referral } \\
\text { n (\%) }\end{array}$ & $\begin{array}{l}\text { Interested } \\
\text { in providing } \\
\text { referral } \\
\text { n (\%) }\end{array}$ & $\begin{array}{c}\text { Currently } \\
\text { provide in } \\
\text { pharmacy } \\
\mathrm{n}(\%)^{7}\end{array}$ & $\begin{array}{c}\text { Interested } \\
\text { in providing } \\
\text { in pharmacy } \\
n(\%)^{7}\end{array}$ & $\begin{array}{l}\text { Not interested } \\
\text { in providing or } \\
\text { referring } \\
\mathrm{n}(\%)\end{array}$ & $\begin{array}{l}\text { Blank } \\
\mathrm{N}(\%)\end{array}$ \\
\hline Alcohol misuse & $6(7 \%)$ & $26(28 \%)$ & $4(4 \%)$ & $33(35 \%)$ & $24(26 \%)$ & 0 \\
\hline $\begin{array}{l}\text { Birth defect } \\
\text { prevention - folic acid }\end{array}$ & $4(4 \%)$ & $20(22 \%)$ & $19(20 \%)$ & $34(37 \%)$ & $15(16 \%)$ & $1(1 \%)$ \\
\hline Breastfeeding & $8(9 \%)$ & $27(29 \%)$ & $1(1 \%)$ & $30(32 \%)$ & $27(29 \%)$ & 0 \\
\hline Diet & $14(15 \%)$ & $20(22 \%)$ & $16(17 \%)$ & $30(32 \%)$ & $13(14 \%)$ & 0 \\
\hline Fall prevention & $6(6 \%)$ & $21(23 \%)$ & $13(14 \%)$ & $39(42 \%)$ & $14(15 \%)$ & 0 \\
\hline Physical activity & $9(10 \%)$ & $24(26 \%)$ & $12(13 \%)$ & $30(32 \%)$ & $18(19 \%)$ & 0 \\
\hline Skin cancer prevention & $8(9 \%)$ & $25(27 \%)$ & $9(10 \%)$ & 36 (39\%) & $15(16 \%)$ & 0 \\
\hline $\begin{array}{l}\text { Sexually transmitted } \\
\text { infection prevention }\end{array}$ & $6(6 \%)$ & $22(24 \%)$ & $5(5 \%)$ & $31(33 \%)$ & $29(31 \%)$ & 0 \\
\hline Tobacco use & $3(3 \%)$ & $13(14 \%)$ & $38(41 \%)$ & $27(29 \%)$ & $12(13 \%)$ & 0 \\
\hline
\end{tabular}

* percentages may not total 100 due to rounding 
Table 3. Ohio community pharmacist $(n=93)$ responses regarding screening services that can be provided in community pharmacies

\begin{tabular}{|l|c|c|c|c|c|c|}
\hline Service & $\begin{array}{c}\text { Currently } \\
\text { provide } \\
\text { referral } \\
\mathrm{n}(\%)\end{array}$ & $\begin{array}{c}\text { Interested in } \\
\text { providing } \\
\text { referral } \\
\mathrm{n}(\%)\end{array}$ & $\begin{array}{c}\text { Currently } \\
\text { provide in } \\
\text { pharmacy } \\
\mathrm{n}(\%)^{7}\end{array}$ & $\begin{array}{c}\text { Interested } \\
\text { in providing in } \\
\text { pharmacy } \\
\mathrm{n}(\%)^{7}\end{array}$ & $\begin{array}{c}\text { Not interested } \\
\text { in providing or } \\
\text { referring } \\
\mathrm{n}(\%)\end{array}$ & $\begin{array}{c}\text { Blank } \\
\mathrm{n}(\%)\end{array}$ \\
\hline Alcohol misuse & $6(6 \%)$ & $26(28 \%)$ & $2(2 \%)$ & $33(35 \%)$ & $24(26 \%)$ & $2(2 \%)$ \\
\hline Blood pressure & $6(6 \%)$ & $7(8 \%)$ & $48(52 \%)$ & $22(24 \%)$ & $9(10 \%)$ & $1(1 \%)$ \\
\hline Cholesterol & $8(9 \%)$ & $13(14 \%)$ & $16(17 \%)$ & $40(43 \%)$ & $15(16 \%)$ & $1(1 \%)$ \\
\hline Depression & $6(6 \%)$ & $29(31 \%)$ & $2(2 \%)$ & $27(29 \%)$ & $27(29 \%)$ & $2(2 \%)$ \\
\hline Hepatitis C & $4(4 \%)$ & $32(34 \%)$ & $2(2 \%)$ & $27(29 \%)$ & $26(28 \%)$ & $2(2 \%)$ \\
\hline HIV & $6(6 \%)$ & $31(33 \%)$ & $2(2 \%)$ & $24(26 \%)$ & $29(31 \%)$ & $1(1 \%)$ \\
\hline Intimate partner violence & $4(4 \%)$ & $28(30 \%)$ & 0 & $22(24 \%)$ & $38(41 \%)$ & $1(1 \%)$ \\
\hline Obesity & $7(8 \%)$ & $22(24 \%)$ & $7(8 \%)$ & $34(37 \%)$ & $22(24 \%)$ & $1(1 \%)$ \\
\hline Osteoporosis & $5(5 \%)$ & $24(26 \%)$ & 0 & $41(44 \%)$ & $22(24 \%)$ & $1(1 \%)$ \\
\hline Tobacco use & $4(4 \%)$ & $17(18 \%)$ & $22(24 \%)$ & $29(31 \%)$ & $20(22 \%)$ & $1(1 \%)$ \\
\hline Type 2 diabetes & $7(8 \%)$ & $13(14 \%)$ & $19(20 \%)$ & $39(42 \%)$ & $14(15 \%)$ & $1(1 \%)$ \\
\hline Tuberculosis & $8(9 \%)$ & $27(29 \%)$ & 0 & $26(28 \%)$ & $31(33 \%)$ & $1(1 \%)$ \\
\hline
\end{tabular}

* percentages may not total 100 due to rounding 
Table 4. Ohio community pharmacist $(n=93)$ responses regarding screening services that cannot be fully provided in community pharmacies

\begin{tabular}{|l|c|c|c|c|c|c|}
\hline Service & $\begin{array}{c}\text { Currently } \\
\text { providing } \\
\text { education } \\
\mathrm{n}(\%)\end{array}$ & $\begin{array}{c}\text { Interested } \\
\text { in providing } \\
\text { education } \\
\mathrm{n}(\%)\end{array}$ & $\begin{array}{c}\text { Currently } \\
\text { provide } \\
\text { referral } \\
\mathrm{n}(\%)\end{array}$ & $\begin{array}{c}\text { Interested in } \\
\text { providing } \\
\text { referral } \\
\mathrm{n}(\%)\end{array}$ & $\begin{array}{c}\text { Not interested } \\
\text { in providing } \\
\text { education or } \\
\text { referrals } \\
\mathrm{n}(\%)\end{array}$ & $\begin{array}{c}\text { Blank } \\
\mathrm{n}(\%)\end{array}$ \\
\hline $\begin{array}{l}\text { Abdominal aortic aneurysm } \\
\text { screening }\end{array}$ & $2(2 \%)$ & $14(15 \%)$ & $3(3 \%)$ & $23(25 \%)$ & $44(47 \%)$ & $7(8 \%)$ \\
\hline BRCA risk assessment and testing & 0 & $21(23 \%)$ & $3(3 \%)$ & $21(23 \%)$ & $3(3 \%)$ & $5(5 \%)$ \\
\hline Breast cancer screening & $1(1 \%)$ & $23(25 \%)$ & $2(2 \%)$ & $21(23 \%)$ & $41(44 \%)$ & $5(5 \%)$ \\
\hline Cervical cancer screening & $1(1 \%)$ & $21(23 \%)$ & $3(3 \%)$ & $23(25 \%)$ & $40(43 \%)$ & $5(5 \%)$ \\
\hline Colorectal cancer screening & $2(2 \%)$ & $22(24 \%)$ & $2(2 \%)$ & $24(26 \%)$ & $38(41 \%)$ & $5(5 \%)$ \\
\hline Lung cancer screening & 0 & $23(25 \%)$ & $3(3 \%)$ & $23(25 \%)$ & $38(41 \%)$ & $5(5 \%)$ \\
\hline $\begin{array}{l}\text { Sexually transmitted infection } \\
\text { screening (i.e., chlamydia, } \\
\text { gonorrhea, syphilis) }\end{array}$ & $2(2 \%)$ & $20(22 \%)$ & $4(4 \%)$ & $21(23 \%)$ & $41(44 \%)$ & $5(5 \%)$ \\
\hline
\end{tabular}

